
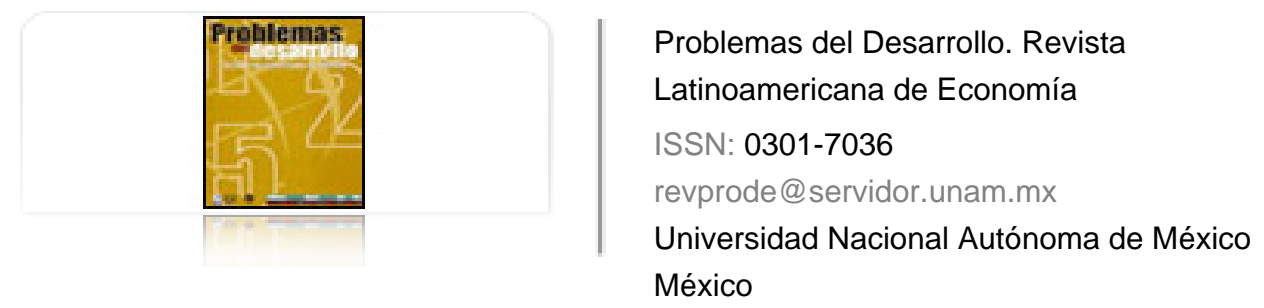

Esquivel Martínez, Horacio

Situación actual del Sistema de Ahorro y Crédito Popular en México

Problemas del Desarrollo. Revista Latinoamericana de Economía, vol. 39, núm. 152, enero-marzo, 2008, pp. 165-191

Universidad Nacional Autónoma de México

Distrito Federal, México

Disponible en: http://www.redalyc.org/articulo.oa?id=11820668009

Cómo citar el artículo

- Número completo

- Más información del artículo

Página de la revista en redalyc.org

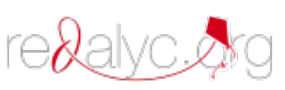

Sistema de Información Científica

Red de Revistas Científicas de América Latina, el Caribe, España y Portugal Proyecto académico sin fines de lucro, desarrollado bajo la iniciativa de acceso abierto 


\title{
SITUACIÓN ACTUAL DEL SISTEMA DE AHORRO Y CRÉDITO POPULAR EN MÉXICO
}

\author{
Horacio Esquivel Martínez* \\ Fecha de recepción: 2 de octubre de 2007. Fecha de aceptación: 21 de enero de 2008.
}

\section{Resumen}

En este artículo se presenta el estado actual del sector de las microfinanzas en México y se hace un breve análisis del marco regulatorio del segmento así como de los principales actores, redes e instituciones participantes en el sector. Sobre este punto, se muestran las características metodológicas de las propuestas de microcrédito más relevantes y de algunas muy características como el caso de microcrédito en Michoacán. Se hace una revisión introductoria que habrá de continuarse sobre los dos modelos prevalecientes hoy en día, el del crédito subsidiado en contraste con el modelo de crédito de mercado, que es el que propone el paradigma de las microfinanzas. Se analizan algunos fundamentos teóricos e históricos relevantes de cada propuesta y se explican las limitantes del crédito subsidiado en términos de la imposición de techos a las tasas de interés y sus secuelas. Se estudian algunas opciones para tener, por un lado, mejor control del sector y, por otro, impulsarlo para que concrete los objetivos planteados en las cumbres de las microfinanzas: llegar a los más pobres, bancarizarlos y combatir la pobreza.

Palabras clave: microfinanzas, finanzas populares, grupo de control, grupo tratamiento, grupo testigo, impacto, pobreza.

* Doctor en Economía en la UNAM; profesor en la Universidad Anáhuac del Sur, UNAM y profesor invitado de la Southern New Hamsphire University. Correo electrónico: horaesquivel@ gmail.com. 


\section{Summary}

This article presents the current state of Mexico's micro-financing sector, briefly analyzing the segment's regulatory framework, as well as the principal actors, networks and institutions that participate in this sector. On this point, it presents the most important methodological characteristics of micro-credit proposals and some very characteristic aspects, as in the case of micro-credits in the state of Michoacán. The article includes an introductory review that will have to be continued, dealing with today's two prevailing models-contrasting the subsidized credit model with the market credit model, as proposed by the micro-financing paradigm. Some relevant theoretical and historical fundamentals are analyzed for each proposal and the limits of subsidized credit are explained in terms of imposing interest rate ceilings and their sequels. Some alternatives are considered which should be continued, on the one hand, to have better control of the sector and, on the other, to promote the concretization of the aims put forward at micro-finance summits, these being to serve the poorest segments, promote banking among them and combat poverty.

Key words: Micro-finance, popular finance, control group, treatment group, witness group, impact, poverty.

\section{Résumé}

Le présent article décrit l'état actuel du secteur des micro-finances au Mexique et fait une brève analyse de son cadre régulateur ainsi que des divers acteurs, réseaux et institutions qui participent dans ce secteur. En ce qui concerne ces derniers, les caractérisques les plus notables des méthodes d'offre de crédit sont présentées, avec certaines très particulières comme c'est le cas du micro-crédit de l'État mexicain de Michoacan. Il est fait une première révision - qui devra être poursuivie - des deux modèles qui prévalent aujourd'hui, le modèle du crédit subsidié et, en contraste, celui du crédit de marché, qui est celui que propose le paradigme de la micro-finance. L'article analyse quelques fondements théoriques et historiques importants de chacune des deux propositions et explique les limites que rencontre le crédit subsidié en termes de plafonds imposés aux taux d'intéret et leurs conséquences négatives. Quelques alternatives sont étudiées qui doivent être suivies afin d'une part d'avoir un meilleur contrôle du secteur, et d'autre part de l'impulser pour qu'il concrétise les objectifs fixés lors des sommets de microfinances: arriver aux plus pauvres, les bancariser et combattre la pauvreté.

Mots clés: micro-finances, finances populaires, groupe de contrôle, groupe traitement, groupe témoin, impact, pauvreté.

\section{Resumo}

O presente artigo apresenta o estado atual do setor das microfinanças no México, faz-se uma breve análise do marco regulatório do segmento assim como dos principais atores, redes e instituições que participam no setor. Sobre este ponto, apresentam-se as características metodológicas das propostas de microcrédito mais relevantes e de algumas muito características como é o caso do caso de microcrédito no Estado de Michoacán, México. Faz-se uma revisão introdutória que se continuará, sobre os dois modelos que prevalecem hoje em dia, o do crédito subsidiado em contraste com o modelo de crédito de mercado, que é o que propõe o paradigma das Microfinanças. Analisam-se alguns fundamentos teóricos e históricos relevantes de cada proposta e explicam-se as limitantes do crédito subsidiado em termos da imposição de tetos às taxas de interesse e suas seqüelas. Estudam-se algumas alternativas que devem ser seguidas com o fim de ter por um lado, melhor controle do setor e por outro, impulsioná-lo para que concretize os objetivos propostos nas reuniões de cúpula das microfinanças: chegar aos mais pobres, "bancarizá-los" e combater a pobreza.

Palavras-chave: Microfinanças, finanças populares, grupo controle, grupo tratamento, grupo testemunha, impacto, pobreza. 


\section{Antecedentes}

$\varepsilon$

1 sistema financiero mexicano no considera las entidades de ahorro y crédito popular como parte integral de éste. Existen leyes adicionales a la Ley de Instituciones de Crédito, como la Ley de Organismos Auxiliares de Crédito y la Ley de Ahorro y Crédito Popular (LACP), que establecen los principios normativos correspondientes a las llamadas instituciones de la banca social (Anaya, 2006).

La LACP busca regular las dos figuras importantes que a la larga deberán adoptar las entidades de ahorro y crédito popular (EACP). Las figuras son Sociedades Cooperativas de Ahorro y Préstamo (SCAP) — sin fines de lucro—, como cooperativa, y Sociedades Financieras Populares (SOFIPO) - con fines de lucro-, como sociedad mercantil. En el futuro, las instituciones del sector social adscritas al marco normativo de la LACP deberán adoptar cualesquiera de dichas figuras (Silva, 2004).

Una característica del llamado sistema de ahorro y crédito popular consiste en que, de acuerdo con la figura legal adoptada, existe un marco normativo que las rige, así como en algunos casos —instituciones microfinancieras- es la Secretaría de Economía (SE) la entidad reguladora, en el caso de las instituciones del llamado sistema de ahorro y crédito popular cuyos actores son uniones de crédito, sociedades de ahorro y préstamo, sociedades cooperativas, cajas solidarias y cajas populares, es la propia Comisión Nacional Bancaria y de Valores (CNBV) la que lleva la batuta.

Es pertinente señalar que corresponde a la Secretaría de Hacienda y Crédito Público (SHCP) la tutela de todo el sistema financiero y que la CNBV funge, mediante la regulación prudencial, como brazo ejecutor de dicha entidad principal hacia las instituciones del sistema de ahorro y crédito popular (SACP). La función del Banco Nacional de Servicios Financieros (BANSEFI), constituido en 2001, (Esquivel, 2007b), consiste en promover la cultura del ahorro entre la población, operar como banco o caja central del SACP y coordinar los apoyos del gobierno central para fortalecer y apoyar la institucionalización del sector (Silva, 2004).

Por lo que toca a las llamadas instituciones microfinancieras (IMF), éstas - como se dijo- son reguladas por la Secretaría de Economía. Por tanto, la CNBV norma a instituciones con figura jurídica establecida por la LACP, mientras que la SE se encarga del sector de las IMF, donde encontramos orgnizaciones no gubernamentales (ONG) y asociaciones civiles (AC) que son catalogadas como microfinancieras.

\section{Sobre la teoría del crédito}

La influencia de los factores monetarios en torno a la determinación de la tasa de interés ha sido un tema largamente debatido dentro de las dos principales escuelas de 
pensamiento económico; por ejemplo, la escuela con raíces keynesianas establece la eficacia de las herramientas monetarias para influir en la tasa de interés de mercado, ello afecta de manera inmedita la toma de decisiones de los inversionistas, tanto en el sector financiero como en el productivo, este último como generador de empleo y capaz de incrementar el poder adquisitivo de la clase trabajadora. Contrario a esta posición, se tiene la denominada escuela monetarista, la cual parte del supuesto de la "neutralidad del dinero" (Mantey, 1997) como consecuencia de la libre movilidad de los precios en los diferentes sectores de la economía.

Las posiciones contrapuestas entre escuelas de pensamiento proporcionan una herramienta valiosa para encontrar las razones por las cuales las personas incurren en solicitudes de microcrédito; es decir, es necesario analizar las razones y los sectores a los que dirigen sus gastos provenientes de préstamos de las instituciones microfinancieras. Estudios recientes muestran que a las zonas marginadas del país denominadas como marginadas económicamente, el gobierno federal las atiende con diferentes programas de apoyo para combatir la pobreza; sin embargo, los resultados que arrojan las encuestas para sondear los impactos de dichos programas son heterogéneos (Esquivel, tesis doctoral, 2007).

Por lo común, los gastos que realizaban los acreditados no necesariamente iban dirigidas al mejoramiento de sus condiciones de vida; muy por el contrario, los dirigían al consumo inmediato e incluso para diversión; ello abriría un nuevo cauce de investigación que rebasa el presente artículo. Los objetivos que persiguen las instituciones crediticias bancarias y las instituciones crediticias microfinancieras tienen desde su origen diferencias sustanciales. Mientras que la primera obtiene sus beneficios en torno a la intermediación financiera, la segunda tiene, en principio, objetivos conceptuales mayormente sociales y de superación de la pobreza.

Así, por ejemplo, como una forma para sustentar los efectos de los recursos financieros en los grupos de atención, se debe analizar la estructura de la economía en la que se labora. Si se parte de un modelo dinámico bajo el supuesto de que parte del ingreso que se percibe lo ahorran con el objetivo de aumentar después los niveles de inversión en sus negocios o directamente para iniciar proyectos de inversión productiva, se tienen diferentes opciones para mantener los ahorros; por ejemplo, pueden mantenerlos en forma de activos financieros, lo que representa una manera de inversión en el sector financiero que permite, a su vez, obtener un rendimiento a plazos. Este modo de manejar los recursos garantiza un incremento en los niveles de consumo real.

Una segunda opción de inversión puede ser física, esto es, productiva y generadora de empleo (objetivo principal de los programas de apoyo a las PYME). En este 
caso, se consideran sólo dos factores productivos, trabajo y capital, que se explican por la ley de los rendimientos decrecientes (Parkin y Esquivel, 2001). La conclusión principal de estas características de los insumos productivos es que a medida que el capital per capita aumenta, el ingreso real per capita se eleva.

A partir del supuesto de que el monto de ahorro viene determinado por la cantidad de recursos obtenidos por el grupo de atención, y considerando únicamente dos factores productivos, éste estará determinado por la curva $S y$ de la siguiente gráfica:

Gráfica 1.

Efectos reales de los apoyos monetarios en la economía

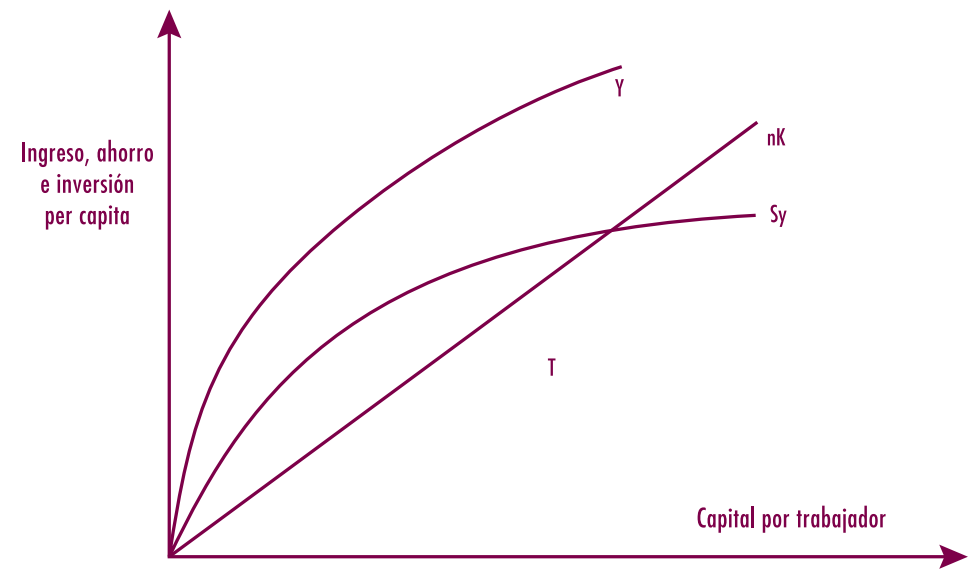

Bajo el esquema de equilibrio dinámico, el ahorro será igual a la inversión necesaria para emplear a toda la mano de obra disponible y con la cantidad de capital ya alcanzada. Al analizar en términos per capita, se observa que esta inversión vendrá representada por la curva $n K$, de tal forma que el equilibrio de largo plazo se logra en el punto $T$. La gráfica muestra que a la izquierda de este punto, cuando el ahorro es superior a la inversión, la intensidad de capital tenderá a aumentar, mientras que a la derecha del punto de equilibrio el capital por trabajador se inclinará a disminuir.

Al considerar que los grupos de atención tienen la posibilidad de invertir sus recursos en opciones financieras, el ahorro ya no necesariamente se canalizará de manera automática a la inversión productiva, sino que una parte de él puede ser destinada a la adquisición de saldos monetarios reales; ello traerá como consecuencia que 
no sólo variará la velocidad con la que se llega al equilibrio de largo plazo, sino que además modificará las características de este equilibrio.

Al suponer que el dinero que se distribuye entre la población sea dinero en términos de billetes que representan un ingreso neto para todos los individuos que conforman el grupo de atención e incrementa su nivel de ahorro, la demanda de dinero se considerará determinada, en primer lugar, por el ingreso real generado $(Y)$; en segundo lugar, por el rendimiento que pudiesen generar los saldos monetarios, es decir, del inverso de la tasa de inflación $(-\dot{p})$; por ultimo, con el rendimiento que ofrezca el activo alternativo, es decir, el capital invertido en la producción $(r)$; se tiene: $M d=f(Y, r,-\dot{p})$.

Por lo anterior, la tasa de crecimiento de los precios será igual a la diferencia entre la tasa de crecimiento de la oferta de recursos monetarios $(\dot{M} \mathrm{~s})$ y la tasa de crecimiento del ingreso real $(\dot{Y}): \dot{P}=\dot{M} s-\dot{Y}$.

Si se consideran los aspectos monetarios de las opciones de inversión, se observa que la tasa de crecimiento del ingreso real estará determinada por la acumulación de capital físico $(\Delta K)$ y el crecimiento de la población $(\Delta N)$, pero a diferencia de lo anterior, esta última no será igual al ahorro $S$, puesto que una parte de ésta se asignará a la obtención de saldos monetarios reales $(\Delta M d)$, de forma tal que:

$$
\begin{aligned}
Y & =f(K, N) \\
\Delta K & =S-\Delta M d
\end{aligned}
$$

Empero, en una economía con opciones financieras, tanto el ingreso real como el ahorro real se verán incrementados cuando crece la oferta de saldos monetarios reales $(M)$ :

$$
\mathrm{Y}+\Delta \mathrm{M}=\mathrm{S}(\mathrm{Y}+\Delta \mathrm{M})+\mathrm{C}
$$

Como conclusión de este pequeño modelo, se puede establecer que ante una variación en el ritmo de crecimiento en los apoyos a los sectores de atención microfinanciera o crediticia, los integrantes tendrán mayores recursos monetarios, lo cual provocará cambios en los precios y en la demanda de dinero que afectarán la parte residual del ahorro destinado a la inversión productiva.

Lo anterior traerá como consecuencia cambios no sólo en la velocidad con que se llega al equilibrio de largo plazo, sino también en las características de ese estado de equilibrio. De forma dinámica: un aumento del crédito a los grupos de atención $(\dot{M} \mathrm{~s})$ aumenta los recursos disponibles. Este incremento de recursos elevará la tasa de inflación $(\dot{p})$, reduciendo la demanda de saldos monetarios reales $(M d)$ y subiendo la proporción de la inversión productiva dentro del ahorro real. 
La mayor acumulación de capital físico per capita acelerará el crecimiento del ingreso real $(\dot{Y})$, al mismo tiempo que reducirá la tasa de rendimiento del capital $(r)$; estos dos últimos factores harán que se eleve nuevamente la demanda de saldos monetarios reales y que se refuerzan efectos secundarios sobre la acumulación de capital físico y el ingreso real.

Dado lo anterior, se puede inferir que un incremento en los programas de apoyo crediticio de las microfinancieras en sectores estratégicos del país no sólo alterará la velocidad del proceso hacia el equilibrio de largo plazo, sino que es muy probable que modifique las características de este equilibrio (por ejemplo, en cuanto a capital e ingreso per capita), dependiendo de los parámetros de la conocida función de producción y de la función de demanda de dinero.

La conclusión principal es que, en teoría, el dinero no es neutral, los programas de apoyo provocarán procesos favorables en la generación de producción y empleo; ello se encuentra claramente en contraposición con el segundo enfoque teórico explicado inicialmente, y que hace referencia al monetarismo, el cual se basa en la teoría cuantitativa del dinero y plantea que un incremento en la cantidad de dinero en circulación es incapaz de influir en las variables reales de la economía, como no sea en un plazo sumamente corto, puesto que a largo plazo sólo elevará los precios de las mercancías.

Hasta aquí se ha explicado el funcionamiento del mercado crediticio desde un punto de vista teórico; a partir de la siguiente sección se hará con casos reales, tomando como estudio el segmento de crédito al llamado sector popular.

\section{Sistema de Ahorro y Crédito Popular (SACP)}

Al hablar del Sistema de Ahorro y Crédito Popular, se habla de un sector paralelo al Sistema Financiero Formal (SFF) que se compone de una diversidad de instituciones y que, a su vez, se divide entre las llamadas sociedades de ahorro y crédito popular y las IMF, donde se encuentra una variedad de organismos, varios de los cuales se abstraen a la regulación e incluso la autorregulación. Ello da pie a confusiones, pues en la actualidad se habla del sector social o banca social, donde se incluye todo un paquete de organismos e instituciones públicos y privados que por dedicarse a mercados de nicho, sobre todo del sector popular, son llamadas instituciones de microfinanzas.

Se hace necesario insistir (Esquivel, 2007a) en que el monto no hace al concepto, sino que es el destino el que lo hace y que, por ejemplo, un crédito al consumo en una tienda de enseres domésticos de las llamadas populares no es un microcrédito; dichas empresas no tienen entre sus objetivos combatir la pobreza, ni dirigir sus esfuerzos 
en apoyo a los pobres, sobre todo mujeres, ni menos aún empoderarlos (Friedmann, 1994). Las microfinanzas surgieron como microcréditos y su prioridad es combatir la pobreza y ofrecer servicios financieros a la gente de escasos recursos para que inicien un pequeño negocio. Responden a una situación de escaso crecimiento económico y poca generación de empleo.

El sector de cajas populares, del que da cuenta el Sistema de Ahorro y Crédito Popular, tiene otra vocación, arraigada principalmente en movimientos de carácter religioso y filantrópico. Por otro lado, no sólo la filosofía sino la dinámica de las cajas de ahorro y crédito popular difiere de las IMF, que tienen como su mercado objetivo a los más pobres de la población. Aquellos que, de acuerdo al Banco Mundial (2007), viven con menos de dos dólares diarios y que representan en el ámbito mundial un mercado superior a los mil millones de personas. Las uniones de crédito, otros integrantes del SACP, tampoco tienen como su mercado de atención a los pobres del medio urbano y menos rural. Se tiene entonces una situación en la que la autoridad regula a un grupo de instituciones que se insertan más o menos en un determinado segmento económico, el de mediana y pequeña empresas (MYPE). Sin embargo, el mercado de microfinancieras se deja en manos de una institución que por su naturaleza no es reguladora, sino promotora, la SE.

Esta dispersión del sector se refleja también en la forma en que se organiza mediante diversas redes — de las que se hablará a detalle más adelante—, cuando en otros países existe una sola (Puente Ibarnegaray, 2006). Lejos de contar con una sola ley, un solo organismo que regule y una sola red que las organice y concentre, se tiene una legislación con huecos y un sector con muy diversos tipos de instituciones que declaran, a pesar de las evidencias en contrario, tener un mismo fin, pero diferentes figuras jurídicas. De este modo, resulta que las instituciones adoptan el esquema que más les convenga y no una que marque el propio sector o al menos una de las dos que establece la LACP.

Lo anterior da como resultado un sector de banca social, como se ha dicho, disperso y con fines a veces abiertamente contrapuestos como puede tenerlos un banco comercial o una institución microfinanciera de combate a la pobreza. El cuadro 1 da muestra del tipo de instituciones del llamado sector de banca social. Algunos analistas (Illanes, 2005) llegan al extremo de hacer sus propias categorizaciones ante las que no existe ningún consenso entre los estudiosos, llamando al sector de uniones de crédito, sociedades de ahorro y préstamo, sociedades cooperativas, cajas solidarias y cajas populares, como banca popular y al de IMF como banca social.

La denominación oficial del sector de las EACP es Sector de Ahorro y Crédito Popular, mismo que está regulado por la LACP, lamentablemente esta ley sólo 
considera a las instituciones que ya se han citado y que también se presentan en el cuadro 1, dejando fuera al universo de las IMF, a las que se da simplemente ese estatus por tratarse de figuras jurídicas no reguladas como ONG o AC. Parte de la labor de analizar estos temas radica en la necesidad de construir las categorías que sirvan como común denominador a todos los autores, evitando así mayores confusiones y puntos de vista sesgados sobre lo qué son las microfinanzas y lo que no forma parte de éstas.

Cuadro 1

Entidades de ahorro y crédito popular

\begin{tabular}{lc}
\hline Entidad & Número de entidades \\
\hline Uniones de crédito (1) & 32 \\
Sociedades de Ahorro y Préstamo (SAP) & 11 \\
Sociedades cooperativas (2) & 157 \\
Cajas Solidarias (3) & 260 \\
Cajas Populares (4) & 220 \\
Total de entidades del sector & 680 \\
\hline
\end{tabular}

${ }^{1}$ Se estima que sólo 32 uniones de crédito (de un total de 266) captan ahorro.

2 Agrupados en cuatro confederaciones y 25 federaciones.

${ }^{3}$ Forma jurídica de sociedad civil.

${ }^{4}$ Cooperativas y asociaciones civiles no agrupadas.

Fuente: Bansefi, 2005.

Aquí se muestra otro caso, la idea de incluir a instituciones bancarias en este sector ha acentuado la tendencia a llamarle del mismo modo a movimientos o iniciativas con muy poco en común, tanto desde el punto de vista de su vocación (misión y visión) como de las figuras jurídicas que adoptan y la entidad responsable de regularlas. La idea de proveer a los pobres de servicios financieros ayuda a bancarizar a este sector y a disminuir la segmentación del mercado. Sin embargo, no se deben soslayar algunos de los riesgos que se enfrentan ante esta nueva ola de instituciones que atienden al mercado de los pobres. Tales riesgos son la saturación del mercado. Es sabido que mucha de la competencia se está concentrando en los 
mismos sectores y zonas geográficas con la sola idea de obtener retornos financieros rápidos como lo afirma el gerente general de BANCOSOL, Kart Koenigsfest (2007).

Lo anterior conduce al otorgamiento de crédito al consumo en detrimento del crédito a la actividad productiva. Ante la necesidad de otras instituciones microfinancieras de mantenerse en el mercado y el acceso a éste de nuevos actores sin la tecnología de microfinanzas, ni el personal adecuado, ni la vocación, se gesta un proceso de segmentación en el que se deja de atender al sector de la microempresa en pro de la pequeña y mediana. Es un proceso paradójico (Koenigsfest, 2007) en que la competencia, principalmente bancaria, obliga a las IMF a atender mercados que ofrecen una rentabilidad más segura, abandonando los principios que dieron origen a las microfinanzas.

Hacia finales de los años noventa se pregonaba el deseo de que la banca comercial participara en el segmento de las microfinanzas, con el argumento de que ello contribuiría a bancarizar el sector, profesionalizarlo, ofrecer multiproductos, mejorar los servicios y bajar las tasas de interés, dando como resultado un círculo virtuoso de mayor ahorro, crédito, crecimiento y disminución de la pobreza.

En la actualidad se ve con recelo la participación de bancos comerciales y de desarrollo; se argumenta que ello puede saturar algunas zonas geográficas donde ya existen estos servicios, se corre el riesgo de abandonar al sector de las microempresas — como se dijo— en sustitución de un sector más desarrollado y que requiere de menores apoyos. Es evidente, además, que los bancos no buscan la rentabilidad social, por lo que la rentabilidad financiera se vuelve el único elemento de juicio al momento de incursionar en un mercado.

Por lo que toca a la participación de bancos de desarrollo, fondos y fideicomisos públicos que incursionan en el mercado, bajando por decreto las tasas de interés, el riesgo que se corre es el de dañar la base del sistema que se fundamenta en la sustentabilidad. Como advierten algunos practicantes y teóricos (Koenigsfest, 2007; Ruiz Durán, 2004; Mckinnon, 1973, Shaw, 1973), si sólo se incorporan nuevos competidores, sean bancos comerciales o de desarrollo con un esquema de techos a las tasas de interés y de búsqueda de beneficios de corto plazo, entonces sí todos los actores del sistema tendrán que empezar a preocuparse. Las tasas de interés en todo caso deben ser diferenciadas, así se tiene una tasa para créditos al sector productivo, otra para el de vivienda, consumo, etcétera.

Las tasas deben fijarse en función a los costos, la oferta, la demanda y la eficiencia. Para lograr disminuirlas, no debe hacerse por decreto sino apelando al uso intensivo 
de tecnología y a la aplicación de nuevos esquemas (tecnologías de crédito) crediticios, como las sucursales o agencias itinerantes. La idea subyacente en este modelo consiste en el reconocimiento de la incapacidad de cualquier IMF de abrir agencias y contratar más oficiales de crédito en todas las zonas geográficas de un país, hacerlo es costoso. Por ello, se están aplicando estos esquemas de agencias itinerantes que van de una zona a otra, evitando así los costos que implica tener una sucursal fija.

\section{Problemas de la falta de control del mercado}

Al no existir intercambios — salvo de forma incipiente — ni adecuados sistemas de información entre las instituciones, se corre el riesgo de sobreendeudar a algunos acreditados. Otros actores han recurrido a la muy cuestionable práctica de comprar carteras de otras instituciones para incrementar rápidamente su portafolio de crédito.

La multiplicidad de actores y figuras en ciertas zonas genera una gran confusión y propicia una falta de control, supervisión y regulación prudencial, sobre todo a partir de figuras no reguladas que atentan contra la estabilidad del sistema. De ahí que para asegurarse de que el dinero llegue a donde los donadores desean, en el mercado microfinanciero han surgido instituciones de corte social especializadas en el manejo de esos recursos. Antes se otorgaba el dinero a las instituciones con la idea de que por tratarse de asociaciones civiles sin fines de lucro o de ONG, los recursos llegarían a los más pobres. Lo que hacen estas instituciones es asegurarse de que el dinero - por ejemplo, los 80 millones de dólares que en 2007 otorgó la Fundación Gates a las microfinanzas, los recursos de la fundación Ford y la USAID, entre muchas otrasllegue a su destino y cumpla con la función esperada.

En el pasado se dependía casi en $100 \%$ de estos donadores; en la actualidad una de las tendencias dominantes en el mercado de las microfinanzas consiste en que a pesar de que dichos recursos siguen siendo muy significativos, se han reducido como proporción del total de las fuentes de ingresos de las IMF, que ahora dependen en mayor medida — hasta en 90\%— de los depósitos de clientes (BANCOSOL, 1997).

\section{Para controlar el mercado: un marco regulatorio}

Un marco regulatorio claro, sencillo que abarque a todo el segmento, además de la organización de todo el sector en una sola red, sería de gran ayuda al momento de analizar y identificar posibles fallas o fracturas, evitando así quiebras generalizadas o insolvencia de acreditados. La falta de información al momento de analizar el sector 
es otro problema al que se enfrentan no sólo analistas sino practicantes y donadores. Al hacer un símil con la política fiscal, se diría que así como resulta más sencillo para una autoridad fiscal administrar pocos impuestos con tasa fija sin exenciones, seguramente resultaría más sencillo regular dos tipos de instituciones, todas pertenecientes a una red - como las que se plantean en la LACP — bajo una misma ley, a diferencia del estado actual en que hay una variedad de figuras jurídicas que se regulan por distintas leyes y organismos regulatorios — $\mathrm{SE}, \mathrm{CNBV}$ — además de organizarse en distintas redes.

Asimismo, un marco regulatorio de uso generalizado ofrece mayor seguridad y certeza jurídica a todos, lo que beneficia principalmente a aquellas empresas que, al carecer de recursos, cuentan con menor capacidad para enfrentar marcos regulatorios adversos. Una gran firma cuenta con equipos de abogados y contadores que les permiten atender las regulaciones e incluso sacar ventaja de ellas, pero para una microempresa, esto es imposible dados los altos costos que ello representa. Por tanto, una ley de uso generalizado y sencillo permite bajar los costos de transacción para las IMF, lo que para los usuarios representaría tener acceso, por un lado, a créditos menos costosos y, por otro, tener mayores garantías de que sus ahorros estarán depositados en instituciones reguladas, con criterios estandarizados de operación.

La profundización del sistema de ahorro y crédito popular es otra ventaja de la consolidación de un adecuado marco regulatorio, permite a las instituciones reguladas ofrecer servicios adicionales al crédito, como son los productos de captación. En efecto, la parte pasiva de la intermediación financiera está prohibida por ley a aquellas instituciones no reguladas, lo cual limita el horizonte de productos que pueden ofrecer a su clientela.

\section{Redes de microfinanzas, fondos y EACP}

Por lo que toca a la forma en que se organizan las instituciones del sector, existen al menos cuatro redes conocidas. La Asociación Nacional de Microfinancieras y Fondos (ANMYF), ProDesarrollo Microfinanzas y Microempresa AC, el Consejo Mexicano de Ahorro y Crédito Popular (COMACREP) y Asociación Mexicana de Uniones de Crédito del Sector Social (AMUCSS) (Esquivel y Hernández, 2006).

\section{Asociación Nacional de Microfinancieras y Fondos}

La ANMYF se constituyó en 2002, agrupa a 60 asociados, microfinancieras y fondos en todo el país que en conjunto cuentan con más de 500 mil acreditados que adminis- 
tran una cartera superior a los cuatro mil millones de pesos y tienen como propósito el impulso a la micro y pequeña empresa en México. ${ }^{1}$

Algunos objetivos de la ANMYF son:

- Representar, promover y llevar a cabo la gestión de los intereses de los asociados ante instancias gubernamentales y privadas, nacionales y extranjeras.

- Apoyo para la obtención de recursos así como asesoría jurídica, contable, administrativa, financiera y tecnológica a las microfinancieras. ${ }^{2}$

\section{ProDesarrollo, Finanzas y Microempresa, AC}

ProDesarrollo, Finanzas y Microempresa, AC es una red nacional de instituciones financieras populares dedicadas a la provisión de servicios de finanzas populares, cuyo objetivo es contribuir al desarrollo económico y al combate para erradicar la pobreza, mediante la asignación de créditos eficientes, servicios de ahorro, asesoría y capacitación a los grupos en situación de desventaja como parte de un proceso de apoyo para un desarrollo sostenible.

Sus afiliadas incluyen practicantes (IMF), redes, participantes (individuos) e instituciones académicas. ProDesarrollo agrupa y representa una parte de actores de la industria, que aplican distintas metodologías, tienen diferentes estructuras institucionales y operan en distintos mercados (urbano, rural, indígenas, pequeñas y microempresa).

En la actualidad ProDesarrollo cuenta con 62 asociados, incluyendo algunas de las instituciones de finanzas populares más grandes de México y dos individuos participantes que otorgan servicios financieros a un millón 100 mil microempresarios del país mediante 682 sucursales o centros de atención.

\section{Consejo Mexicano del Ahorro y Crédito Popular (COMACREP)}

El COMACREP es una institución de representación sectorial, con personalidad jurídica y patrimonio propios. Su propósito fundamental es fortalecer los vínculos naturales y metodológicos de sus asociadas, así como representar eficazmente al sector de ahorro y crédito popular. Busca instaurar políticas públicas que favorezcan su desarrollo para dotar a todo el sistema de valores agregados por efecto directo de

1 Véase: http://www.fondeso.df.gob.mx/noticias/detalleNoticias.html?id_noticia=12 y http:// www.fondeso.df.gob.mx/memoria/3er_taller/AMNYF.pdf.

2 Véase el sitio del Fondo de desarrollo social del DF, miembro fundador de ANMYF: http://www. fondeso.df.gob.mx/noticias/detalleNoticias.html?id_noticia=12 
la concentración de la fuerza sectorial en una sola vía institucional. El COMACREP representa a ocho organizaciones:

1. Consejo Coordinador Nacional de Cajas Solidarias

2. Federación de Cajas Populares Alianza

3. Asociación Mexicana de Uniones de Crédito del Sector Social (AMUCSS)

4. Federación Mexicana de Entidades de Ahorro y Crédito (FMEAC)

5. Federación Regional de Cooperativas de Ahorro y Préstamo Centro-Sur

6. Federación Regional de Cooperativas de Ahorro y Préstamo Noreste

7. Federación Sistema Coopera

8. Federación Nacional de Cooperativas Financiera UNISAP

En su origen, las cajas populares en México fueron organizaciones informales. Se desarrollaron como un trabajo voluntario de sus asociados, no había empleados ni gerentes, éstos surgieron aproximadamente en $1970 .{ }^{3}$

\section{Asociación Mexicana de Uniones}

de Crédito del Sector Social (AMUCSS)

La AMUCSS tiene más de 15 años de experiencia en la creación, promoción, constitución y operación de instituciones financieras rurales de México. Fue promotora de una red de uniones de crédito rurales, de la creación de fondos de autoaseguramiento, de cooperativas, de cajas de ahorro y crédito y microbancos en diversas regiones del país. Ha desarrollado desde hace más de 10 años cierta capacidad en el campo de las microfinanzas rurales.

La AMUCCS se integra por cuatro uniones de crédito campesinas, siete redes de microbancos rurales y tres cooperativas de ahorro y crédito y otros organismos y nuevas instituciones financieras rurales (IFR), ubicadas en las zonas rurales pobres y marginadas del país. Éstas eligen, mediante asamblea, un consejo directivo, que a su vez nombra una dirección general, y ésta a un grupo de asesores para diseñar, establecer y ejecutar los servicios y funciones necesarias para la construcción y desarrollo de las instituciones financieras rurales al servicio de las familias pobres. La AMUCCS forma parte, a su vez, de la red ProDesarrollo.

3 Véase Ramón Imperial Zúñiga: “Consolidación y transformación de la caja popular mexicana”, http://64.233.169.104/search?q=cache:D7R53wWpePIJ:soporte.sagarpa.gob.mx:9090/ SAG-FIRCO/DownloadSrv\%3Fnombre\%3DCajaspopulares.pdf+caja+popular+mexicana\&h $\mathrm{l}=\mathrm{es} \& \mathrm{ct}=\mathrm{clnk} \& \mathrm{~cd}=9 \& \mathrm{gl}=\mathrm{mx}$ 


\section{Organismos del gobierno federal: FONAES}

El Fondo Nacional de Apoyo para Empresas de Solidaridad (FONAES) es un órgano desconcentrado de la Secretaría de Economía que atiende iniciativas productivas de emprendedores de escasos recursos organizados en las llamadas empresas de solidaridad. Los apoyos consisten en acceso a recursos y apoyo en la constitución y consolidación de las compañías del sector social rural y urbano.

El FONAES promueve entre sus beneficiarios que se constituyan en empresas sociales, potencien su capital social, adopten nuevas tecnologías, se integren en sociedades de trabajo y se organicen para generar esquemas de capitalización. Las cajas solidarias son entidades de ahorro y crédito social para la población de bajos ingresos del sector rural sin acceso a otras fuentes de financiamiento. Surgieron en 1993, entre productores del campo para reorientar las recuperaciones de crédito a la palabra en cajas de ahorro y préstamo.

\section{BANSEFI}

Como parte de la política de financiamiento al sector popular, destaca Banco del Ahorro Nacional y Servicios Financieros (BANSEFI), al que se le han encomendado tres tareas fundamentales:

1. Continuar promoviendo el ahorro como hasta ahora lo venía haciendo el Patronato del Ahorro Nacional (PAHNAL). Para ello, se cuenta con más de 500 sucursales en toda la República y a la fecha más de un millón de cuentas que crecen mensualmente en alrededor de 10,000 nuevos clientes. BANSEFI mantiene una política de no cobrar comisiones, tratar de ofrecer las mejores tasas de mercado y la apertura de cuentas con montos bajos.

2. Transformar a BANSEFI en el banco de las organizaciones del ahorro y crédito popular consideradas en la LACP. En este sentido, una de sus tareas fundamentales es servir a estas organizaciones como banca de desarrollo de segundo piso con servicios que les permitan mejorar sus ingresos, reducir sus costos y eficientar sus procesos, así como ampliar la gama de servicios que ofrecen a sus socios y clientes.

3. Coordinar temporalmente los apoyos que el gobierno federal está asignando al sector para facilitar su transformación y colocarlo como un componente estratégico del sistema financiero. Estos apoyos están siendo financiados por organismos multilaterales, el Banco Mundial y el Fondo Multilateral de Inversiones del Banco Interamericano de Desarrollo (BID). 
Las sucursales de las organizaciones que se transformen a la LACP junto con las sucursales de BANSEFI conformarán la Red de la Gente. Ésta está siendo utilizada para distribuir programas gubernamentales, como Oportunidades y Procampo. Otros servicios que se están distribuyendo con esta red son remesas y seguros de salud. Las tareas de transformación de más de 600 organizaciones y sus más de dos millones y medio de socios es un reto para BANSEFI.

Programa Nacional de Financiamiento al Microempresario (PRONAFIM)

El 19 de febrero de 2001 se publicaron en el Diario Oficial de la Federación (DOF) las Reglas de Operación del Fondo para la Micro, Pequeña y Mediana Empresa, integrado por cinco fondos y programas entre los cuales se encontraba el Programa de Banca Social y Microcréditos (PROBASOMI) a cargo de la Secretaría de Economía.

Su principal objetivo fue crear mejores oportunidades de desarrollo entre la población de bajos recursos, mediante el acceso inicial al crédito y al microcrédito (sic). El 17 de mayo de 2001 fue celebrado el Contrato Constitutivo del Fideicomiso del Fondo Nacional de Financiamiento al Microempresario con la participación de la SHCP como fideicomitente y como fiduciaria Nacional Financiera SNC.

El 18 de mayo del mismo año se publicó en el DOF el acuerdo por el que se modifica la denominación del Programa de Banca Social y Microcréditos al de Programa Nacional de Financiamiento al Microempresario, el cual sería administrado mediante el FINAFIM. El PRONAFIM está conformado por dos fideicomisos: FINAFIM y FOMMUR.

FINAFIM: Fideicomiso del Programa Nacional

de Financiamiento al Microempresario

Es el órgano encargado de administrar y otorgar los recursos a las instituciones de microfinanciamiento e intermediarios para que éstos, a su vez, los proporcionen a la población objetivo; además apoya a estas mismas instituciones en la adquisición de software, mobiliario y equipo de cómputo, así como otros apoyos de carácter de no recuperables para el establecimiento de sucursales, capacitación, asistencia técnica, participación en foros, mesas de trabajo y actividades organizadas por el PRONAFIM o por organizaciones del sector, nacionales e internacionales. ${ }^{4}$

4 Para una lista de microfinancieras incorporadas al Pronafim, véase: http://www.economia.gob. mx/pics/p/p714/Microfinancieras_incorporadas.pdf 
FOMMUR: Fideicomiso del Fondo

de Microfinanciamiento a Mujeres Rurales

Se constituyó en el año 2000 para establecer un mecanismo de microfinanciamiento que permitiera proporcionar microcréditos accesibles y oportunos a las mujeres del medio rural que por su condición careciesen de acceso a estos servicios, y cuyos créditos a su vez fueran rentables y recuperables a corto y mediano plazos.

Su finalidad es impulsar el autoempleo y las actividades productivas, así como la adquisición de habilidades empresariales básicas y la práctica de ahorro entre las mujeres de escasos recursos del medio rural. El 29 de septiembre de 2003, mediante convenio modificatorio, se establece que la operación de FOMMUR queda a resguardo del PRONAFIM.

\section{Fondos y Programas Locales:}

Fondo Jalisco (FOJAL)

El FOJAL se crea el 18 de junio de 1985, mediante celebración de contrato de un fideicomiso entre el gobierno estatal de Jalisco como fideicomitente, Nacional Financiera SNC como fiduciaria y las micro y pequeñas empresas del estado como fideicomisarios; es así como se creó el fideicomiso Fondo Estatal de Fomento Industrial de Jalisco.

La principal finalidad del FOJAL es otorgar una respuesta a las necesidades de asesoría integral, capacitación y financiamiento para las micro, pequeñas y medianas empresas locales, fomentando con ello su creación, sobrevivencia y consolidación ( sic). Atiende microempresas de 30 a 50 empleados, otorgando crédito tradicional, ya sea de habilitación y avío, para apoyar al sector agropecuario en la adquisición de materia prima o refaccionario para adquisición de activio fijo. Los plazos son de 24 a 48 meses respectivamente.

\section{Fideicomiso Programa Emprendedores}

El programa Emprendedores es un fideicomiso público constituido en julio de 2000. Inició operaciones vía Emprendedores de Nuevo León, AC, en agosto de 2000. Su misión es apoyar, mediante capacitación básica y el otorgamiento de microcréditos, a todos los habitantes de Nuevo León de escasos recursos, que no tienen posibilidades de ser financiados por la banca comercial y que a juicio del programa cuenten con capacidad emprendedora para iniciar una actividad productiva. 
Durante 2003 se otorgaron 5,969 créditos por un monto de $\$ 17,347,000$ con un promedio de crédito de $\$ 2,906$. De acuerdo con el programa, se crearon 132 nuevos empleos y se fortalecieron 2,210. La cartera vigente ascendió al cierre de 2001 a un total de 2,117 clientes, por un monto de $\$ 3,930,556$; la mora de uno a 28 días se ubicó en $\$ 583,000$ y el monto de cartera en riesgo de 29 a 89 días en $\$ 181,000$ y un promedio de cartera en riesgo acumulada de $1.88 \%$.

\section{Fondo para el Desarrollo Social de la Ciudad de México}

Se constituyó como Fideicomiso Público de Inversión y Administración del Gobierno del Distrito Federal; donde el fideicomitente y el fideicomisario es el gobierno capitalino por medio de la Secretaría de Finanzas, el fiduciario es Nacional Financiera, SNC, y el órgano máximo de control es el comité técnico.

Para promover uno de los principios prioritarios del Gobierno del Distrito Federal, lo que denominan desarrollo con justicia social, y de acuerdo con la decisión -in pectore - del jefe de Gobierno, de crear una institución financiera de otorgamiento de crédito subsidiado, nace el 5 de julio de 2002 el Fondo para el Desarrollo Social (FONDESO) de la Ciudad de México, en sustitución del Fondo de Desarrollo Económico (FONDECO) del Distrito Federal que se constituyó en 1996. El antecedente anterior al FONDECO fue el Fondo para el Desarrollo Económico y Social del Distrito Federal (FONDEDF), fundado en 1989 con el objeto de regular el comercio informal.

El FONDESO otorga apoyos crediticios y asesoría para iniciar o consolidar proyectos productivos que permitan elevar la calidad de vida de la población, principalmente la de menores recursos y que se ubiquen dentro de las zonas de atención del programa.

La creación del FONDESO es una acción que se inscribe dentro del Programa General de Gobierno del Distrito Federal 2001-2006, en su apartado de Progreso con Justicia; así como en la Política de Desarrollo Económico del Distrito Federal.

El objetivo del programa de microcréditos del fondo es fomentar los proyectos de negocios y autoempleo, mediante el otorgamiento de apoyos crediticios a grupos solidarios formados por cinco y hasta 15 personas, en donde el grupo solidario funge como aval. La población objetivo para este programa es aquella que se ubica en las zonas de mayores índices de marginación y pobreza. Para determinar lo anterior se seleccionaron 866 Unidades Territoriales del Distrito Federal.

Los microcréditos se otorgan por etapas, hasta un máximo de cuatro para una misma persona, con montos que van de $\$ 3,000$ hasta $\$ 12,000$ en pagos quincenales desde ocho hasta 20 quincenas. 


\section{Programa de microcréditos Confianza}

en las Mujeres (ConMujer)

Programa del gobierno del estado de Michoacán, constituido en el sexenio del gobernador Lázaro Cárdenas Batel. Se diseñó a imagen y semejanza del programa de Microcréditos del Gobierno del Distrito Federal (GDF). Es previsible que este programa desaparezca en caso de que haya cambios de orientación en el ámbito gubernamental.

El programa otorga créditos de 500 hasta 2,500 pesos. Impone pagos semanales fijos a plazo de 16 semanas. Establece ahorro obligatorio de 2\% mensual sobre el monto original y cobra una tasa de $24 \%$ anual.

Si se realizan pagos puntualmente, el acreditado puede solicitar la misma cantidad nuevamente o solicitar el doble que se pidió la primera vez, hasta llegar a un monto máximo de $\$ 10,000$. Para tener acceso al programa se necesita ser mujer en grado de pobreza con ingresos mensuales no mayores a cuatro salarios mínimos, formar grupos de cuatro a seis mujeres, por lo que se trata de una réplica del esquema de Grupo Solidario.

El ahorro es obligatorio y sirve para cubrir créditos no cubiertos por alguna acreditada o por el grupo. Si todas cumplen, el incentivo es que podrán solicitar un nuevo préstamo por la misma cantidad, por el doble que el primero o bien al final del ciclo podrán retirar la cantidad que aportaron por ese concepto o incrementarlo con las nuevas aportaciones que realicen durante el siguiente préstamo.

Este programa es todavía bastante nuevo como para realizar una evaluación exhaustiva, sin embargo se puede adelantar que se trata de una acto muy común de gobierno, por lo que sus alcances pueden agotarse en cuanto los niveles de recuperación disminuyan, cosa que sucede en estos tipos de programas, en la medida que los ciclos crediticios van creciendo y la situación financiera va empeorando.

\section{Análisis de metodologías de crédito subsidiado vs. metodologías de mercado}

Una explicación a los modelos de crédito subsidiado puede ser lo que se ha denominado modelos de oferta adelantada (Esquivel, 2006i). Este modelo consiste en que ante la insuficiente oferta crediticia, la banca de desarrollo intentó cubrir la brecha entre demanda y oferta de crédito mediante el otorgamiento de empréstitos por debajo de su costo real. De esta forma se tenían mayores volúmenes de crédito, a tasas más bajas que las que se encontraban en el mercado. A este efecto se le conoce en la 
teoría económica como imposición de techos a las tasas de interés (Mckinnon 1973; Shaw 1973).

La idea que subyace al modelo de crédito subsidiado establece que el crédito barato es más accesible para las personas pobres. El modelo de oferta adelantada a la demanda ilustra esta idea. La mayor oferta hace bajar las tasas e incrementa los volúmenes.

Por su parte, el modelo de crédito con un enfoque de mercado establece, a su vez, que los intereses deben ser sostenibles para asegurar que todos —en especial los que requieren de capital para emprender un negocio, y que por lo general son los más pobres - tengan acceso al crédito. La idea subyacente en este enfoque es que en la medida que los créditos incorporan costos asociados, éstos pueden fluir ininterrumpidamente a diferencia de un enfoque subsidiado, donde por su condición intrínseca no es posible cubrir los costos de captación y transacción principalmente.

\section{Los créditos son fungibles}

Se ha explicado también (Mansell, 1995) cómo los recursos son fungibles, es decir, que se destinan para fines distintos para los que se pidió un crédito. Cuando un crédito no cubre los costos principales de su operación (costos de transacción) y de captación (pago a ahorradores), hay mayores incentivos para que la gente o los grupos que los piden no paguen, sobre todo porque la institución no está interesada en recuperarlos, pues independientemente de pérdidas, recibe transferencias. La razón es que una institución que subsidia el crédito en realidad no está cobrando. Aun en el caso de la banca de desarrollo, debieran cubrirse los costos asociados a la operación. Incluso si las fuentes de recursos no son las propias del giro financiero, como instrumentos de deuda, colocaciones y captación.

El crédito por debajo de su costo propicia una demanda que supera su oferta; cuando ello sucede, la autoridad o institución que otorga los recursos debe establecer un criterio de selección distinto a la calidad de un proyecto. Se benefician causas más que proyectos, se reparten los recursos en forma de renta más que como crédito y al final se tiene un efecto similar al de la selección adversa: proyectos de mala calidad que incrementan el quebranto a la institución. Este círculo vicioso persiste hasta que se hace financieramente insostenible para la institución seguir prestando a fondo perdido o cuando la autoridad de la que ésta depende decide suspender el subsidio (Luis F. Aguilar, 1996).

Evidentemente una institución privada que vive de su propia operación establecerá un criterio estrictamente financiero, pronegocio y comercial para decidir a quién 
prestar. No obstante, una institución gubernamental del tipo de las que otorgan crédito subsidiado establecerá un criterio no financiero y no lucrativo, señalando que es un sentido social o la búsqueda de rentabilidad social aquello que la impulsa para otorgar crédito. Por tanto, debe elegir qué criterio utilizar para decidir a quién prestar y a quién no. Este criterio, al no ser de naturaleza financiera, será de connivencia (Esquivel, 2001). De esta forma, es posible emplear o destinar el crédito más fácilmente a un fin distinto al que se pacta en un contrato.

\section{Efecto del techo a la tasa de interés}

Diversos gobiernos han utilizado la imposición de techos a la tasa de interés como forma para la entrega de recursos (CGAP, 2007). La evidencia muestra que este mecanismo lesiona más que ayudar a la economía de la gente pobre, limitando su acceso a dichos servicios: hacen más difícil para los intermediarios formales cubrir sus costos, lo que les complica severamente la operación hasta dejarlos fuera del mercado, dando como resultado el mecanismo de represión financiera; los clientes más pobres que requieren de financiamiento se quedan sin este servicio o bien deben recurrir a mecanismos informales de financiamiento que suelen ser mucho más caros; asimismo, propician una menor transparencia acerca de los costos del crédito en la medida en que los acreedores compensan una menor tasa con los llamados costos ocultos y comisiones.

A pesar de que los techos a las tasas de interés no tienen el efecto deseado por sus practicantes, principalmente los bancos de desarrollo, las preocupaciones de las microfinancieras acerca de los altos costos son válidas (Esquivel, 2007). La competencia parece ser el medio idóneo para reducir los costos de transacción, principal componente del costo elevado de la industria microfinanciera. De hecho, los costos de los microcréditos son elevados, no porque prestar a los pobres sea intrínsecamente más riesgoso, sino por el costo adicional de administrar créditos pequeños; por ejemplo, 1,000 créditos de 1,000 pesos en vez de un solo crédito de un millón de pesos.

\section{La propuesta del crédito}

de mercado: las microfinanzas

El resultado del esquema de crédito subsidiado es una descapitalización de facto, pues la oferta de crédito se agota en cuanto se acaban los recursos para prestar, aun cuando se recupere $100 \%$ de lo prestado. Por ejemplo, si se prestan $\$ 100$ y los costos de transacción de los recursos suman $\$ 10$ (equivalente al 10\%) más 3\% por costo de fondeo y $3 \%$ por no recuperación de créditos, la tasa de interés sería de $16 \%$. Sin 
embargo, por tratarse de un crédito con subsidio de $10 \%$, tendríamos una tasa neta para el acreditado de 6\%. Por tanto, la institución que debe recuperar en teoría 116, sólo recupera 106. En cada crédito similar otorgado faltarían $\$ 10$ para cubrir costos, de tal forma que del capital original, bastarían sólo 10 créditos para descapitalizarse totalmente. Es decir, se trata de un capital que decrece con cada crédito otorgado. Al final, sólo existen dos opciones, recibir más transferencias o bien cerrar.

En México hay ejemplos de instituciones que tuvieron que cerrar cuando la pérdida económica era notoriamente mayor a cualquier rentabilidad social. El campo es un ejemplo de ello. El BANRURAL, una institución diseñada para perder dinero en aras de una rentabilidad social agregada, tuvo que cerrar ante el rotundo fracaso de su estrategia. Evidentemente, la problemática era mucho más compleja, pérdidas por carteras no recuperadas y pasivos laborales acumulados. Sin embargo, al final, la incapacidad de funcionar como entidad financiera sana fue lo que la llevó al fracaso. Si el resultado hubiese sido distinto, seguramente no tendríamos un campo que genera $6 \%$ del PIB con $20 \%$ de la población económicamente activa (Alponte, 2003).

La respuesta de las microfinanzas consiste, siguiendo nuestro ejemplo, en que si la institución tiene un costo de fondeo de $16 \%$, cobrará una tasa de $26 \%$. Es una lógica lucrativa, hay que señalarlo con claridad. El valor de la propuesta radica en la claridad de sus objetivos. Las microfinanzas buscan empresarios que atiendan a un sector social mayoritario, que profundicen la oferta de servicios en el sector, donde por la falsa perspectiva de una escasa rentabilidad los bancos comerciales no habían participado, dejando a todo un amplio sector de la población inerme ante la nula oferta de crédito y dependiendo de fuentes informales como la usura, los préstamos familiares, las tandas, las casas de empeño, etcétera. Varios de esos modelos cobran tasas de $10 \%$ diario o más.

Entre la ausencia de servicios financieros tradicionales y los negocios de usureros, surge el microcrédito como oferta de mercado. Yunus lo señala nítidamente (2007), las microfinanzas son un negocio. No podría ser de otra manera, dado que más allá de calificativos de carácter moral, reconocen costos que es necesario financiar.

En otro tiempo eran las transferencias de recursos fiscales las que llenaban los huecos financieros que dejaban instituciones muy ineficientes, cuyos gastos se iban en buena medida a cubrir sueldos, salarios y toda clase de gastos corrientes. El modelo de microfinanzas depende más de la operación propia del negocio, de la captación de recursos por los que se paga un interés. Sólo así se garantiza que la operación permanezca en el tiempo y que se cuente con empresarios dispuestos a atender un segmento que demanda servicios financieros diversos: ahorro, crédito, seguros, pago 
de remesas y que el gobierno por sí sólo no puede atender. Menos aún subsidiando la operación ad infinutum.

\section{Reflexiones finales: retos pendientes de las microfinanzas}

En relación con los objetivos planteados por las propias instituciones y el sector de microfinanzas, a la fecha el saldo arroja más retos pendientes que logros obtenidos. Los temas pendientes persisten: disminución de la pobreza y bancarización de la población de bajos ingresos, un mercado cercano a 13 millones de familias de un total de 22.5 millones, es decir, $57 \%$ de familias sin acceso a servicios financieros. En términos de población, hablamos de $35 \%$ sin estos servicios. Todo ello a pesar de que el sector de microfinancieras ha crecido sustancialmente en los últimos 10 años, atendiendo a un mercado de no menos de cinco millones de personas por medio de 600 instituciones de diverso tipo, distribuidas en 2,500 sucursales (Prodesarrollo, 2007).

Para lograr que el sistema de microfinanzas evolucione, se requiere de un marco regulatorio adecuado, que sea general y de bajo costo para las instituciones, que simplifique las operaciones y que incluya a todos los actores. La dispersión del sector en México es un problema que se refleja en la calidad de los servicios. Hay multiplicidad de actores de los que no se sabe exactamente a qué se dedican. Hacen microfinanzas o dan crédito al consumo, buscan combatir la pobreza o desean rendimientos rápidos sobre la inversión.

Estas relaciones son una pequeña muestra de la divergencia que hay entre unos y otros actores. Sobre los costos, es evidente que muchas instituciones son renuentes a regularse porque ello implica grandes costos que se reflejarían necesariamente en el precio de los servicios, ya de por sí caros. Pago de contribuciones, realización de trámites para los que se requiere un área específica, informes trimestrales a la CNBV, son sólo algunos de los más evidentes. Generalizar y uniformar criterios ayudaría a abatir esos costos adicionales que sólo las más grandes instituciones tienen capacidad de afrontar.

Otro gran problema es el de la información, no existe una que sea generalizada sobre los acreditados, sólo de manera incipiente por medio del Círculo de Crédito o el Buró de Crédito, lo que es un paso en la dirección correcta. Ello ayudará a disminuir los problemas asociados a la información asimétrica (Esquivel, 2006 a, b, c).

Por otro lado, el problema informativo no se reduce a los acreditados, también es extensivo a las organizaciones. En efecto, no se tiene información sobre las instituciones, nos encontramos con registros parciales sobre instituciones que no son propia- 
mente microfinancieras, como es el caso de cajas de ahorro, ONG, asociaciones civiles, uniones de crédito, fideicomisos públicos o entidades de los gobiernos estatales, de los que ya se han dado algunos ejemplos y que popularizan prácticas que son mezcla de crédito subsidiado con algunos rasgos de microfinanzas. Estas instituciones tienen criterios muy laxos tanto de otorgamiento como de seguimiento y recuperación de crédito. Precisamente lo que ninguna institución seria en la materia viene realizando.

Se requiere de la inclusión de actores que hagan microfinanzas, no sólo crédito al consumo para el sector popular, o peor aún, crédito subsidiado y fungible que jamás llega a esos estratos. Sólo de esta forma será posible llegar a la meta de bancarizar al sector, logrando una mayor penetración con intermediarios microfinancieros que ofrezcan una gama de servicios y productos - multiproductos—acorde con las necesidades, como servicios de pago de remesas, seguros, vivienda, ahorros y desde luego crédito productivo.

El gran reto pendiente consiste en reducir los costos, además de una regulación adecuada que tenga como principales características que sea de aplicación general, sencilla y de bajo costo. El uso de la tecnología de manera intensiva será un elemento clave, el otro, adoptar nuevas formas de hacer microfinanzas — como sucursales móviles - para lograr, por un lado, generar economías de escala y, por otro, mayor penetración en sectores hasta ahora no atendidos.

En efecto, las metodologías que funcionan de forma incipiente en mercados microfinancieros más desarrollados, como el boliviano, consisten en la instauración de agencias móviles que permitan justamente bajar los costos de transacción.

El uso racional de recursos provenientes de donadores es otro factor que se debe considerar, también en esto existe un precedente en la figura de empresas sociales que administran los recursos provenientes de esa fuente y se aseguran de que lleguen al mercado objetivo y se empleen de una forma más eficiente.

El impacto sigue siendo una materia de debate. Los economistas que realizan esta tarea no han llegado a un consenso sobre un método exacto para medirlo; aun considerando numerosas variables como medida del impacto, no se ha arribado a una selección de variables que permitan una medición exacta. El uso del grupo de control como metodología de medición de impacto implica algunos retos, los mayores tienen qué ver con la identificación de dos grupos con características iguales y en eliminar variables - como remesas- que afecten exógenamente el ingreso, la educación o cualquier otra que se pretenda medir.

Dicho de otra forma ¿cómo determinar que no ha habido fuentes adicionales de ingreso en uno u otro grupo que afecten el ingreso y que sea erróneamente atribuido al efecto de un microcrédito? La pregunta queda abierta, sin embargo lo que indican 
los estudios, con todo y sus limitaciones, es que los microcréditos sí están funcionando en el incremento del ingreso, en la provisión de servicios financieros a los pobres $\mathrm{y}$ en el fomento del autoempleo que permite a los beneficiarios tener un modo digno de mantenerse a sí mismos y a sus familias. Se han visto otras opciones como son los programas clientelares, de los que dimos cuenta de algunos muy característicos, formas de transferencia, subsidios o hasta seguros de desempleo, que no se basan en propuestas autosustentables, cosa que sí es una característica de las microfinanzas.

Por ello, una de las grandes diferencias de las microfinanzas respecto a propuestas de gobierno o de transferencia directa consiste en que las microfinanzas son una opción de mercado que reconoce costos y pretende cubrirlos en lugar de soslayarlos como hacen algunos programas gubernamentales. Dichos costos no desaparecen, no quiere decir que el gobierno no los tenga en la aplicación de programas o que sea tan eficiente que los desestima, sino que los transfiere al grueso de la población mediante impuestos.

Las microfinanzas han sido durante los últimos 34 años una respuesta eficaz al fracaso del modelo estatal de financiamiento a los más pobres, a la base de la pirámide. Se ha hecho con metodologías no tradicionales que han permitido allegar recursos a dicho segmento, de una forma segura y a un menor costo que los servicios a los que tradicionalmente tienen acceso como son las fuentes informales de crédito, usureros, agiotistas o incluso casas de empeño (las llamadas pawn shops). No obstante, persiste el reto de bajar aún más los costos, manteniendo al mismo tiempo la seguridad en las operaciones, toda vez que al transitarse de un modelo que dependía principalmente de donaciones a otro que se sustenta en la captación, hay que garantizar la recuperación de los créditos.

Al mismo tiempo, se mantiene el enorme reto de llegar a los deciles más bajos de la población, lo que se denomina alcance, a una escala que cubra todo el segmento — cobertura - que demanda sus servicios. Y también deben considerarse los costos tradicionales (transacción, fondeo y costo por créditos no recuperados), más los que impone la actividad regulada sin menoscabo de un elevado índice de recuperación de créditos. 


\section{Bibliografía}

Aguilar Villanueva, Luis F. y Donald S. Van Meter, La implementación de las políticas, México, Miguel Ángel Porrúa, 1996.

Alponte, Juan María, "De Madero al TLC", México, El Universal, 2 de diciembre de 2002.

Esquivel Martínez E. Horacio, Impactos económicos y sociales de los programas de microcrédito", tesis doctoral, México, UNAM, 2007.

"Las microfinanzas como respuesta a la información asimétrica: el caso de la ciudad de México", Comercio Exterior, México, agosto, 2006.

, "Microcrédito y Combate a la Pobreza a través de Instituciones Financieras Sustentables", Ejecutivos de Finanzas, febrero, 2006.

, Hernández Ramos, Ulises, "Microfinanzas en el sector rural", Agronuevo, octubre de 2006.

, "Profundización financiera y costos de las microfinanzas", Ejecutivos de Finanzas, octubre, 2007.

, Propuesta de Aplicación de la Nueva Gerencia Pública para el Desarrollo de la Banca Social: el caso de FONDECO-DF, tesis de maestría, INAP, 2001.

" "Crecimiento Económico e Información Asimétrica", Economía Sociedad y Territorio, enero 2007a.

"Finanzas Populares en la Ciudad de México", Ejecutivos de Finanzas, abril, 2007b.
Friedmann, John, Empowerment: The Politics of Alternative Development, Economic Geography, vol. 70, núm. 4, octubre de 1994, pp. 417-419.

Helms Brigit and Reille, Xavier, "Interest rate Ceilings and Microfinance: the story so far", Occasional paper, núm. 9, CGAP, septiembre, 2004.

Illanes, Emilio, "La otra banca", Ejecutivos de Finanzas, núm. 3405, 1 de octubre de 2005.

Mansell Carstens, Catherine, Las Finanzas populares en México, ITAM, 1995.

Mantey, Guadalupe, Lecciones de economía monetaria, México, UNAM, 1997.

McKinnon R., Money and Capital in Economic Development, Washington, DC, Brookings Institution, 1973

Parkin, Michael y Esquivel, Gerardo, Microeconomía, México, Addison Wesley, 1999.

ProDesarrollo, Benchmarking de las Microfinanzas en México: desempeño y transparencia en una industria creciente, ProDesarrollo y MIX., 2007.

Ruiz Durán, "Los desbancarizados: el problema de los mercados financieros segmentados", Comercio Exterior, vol. 54, núm., 7, p. 566, México, julio, 2004.

Shaw, Edward, Financial Deepening in Economic Development, Nueva York, Oxford University Press, 1973.

Silva, Aarón, "La respuesta gubernamental a la falta de servicios microfinancieros", $\mathrm{Co}$ mercio Exterior, vol. 54, núm., 7, p. 575, México, julio, 2004.

\section{Páginas de Internet consultadas}

Páginas de Internet consultadas

AMUCCS, www.amuccs.org, 20/08/07.

Anaya Mora, Miguel Luis, La banca de desarrollo en México, http://www.eclac.cl/ publicaciones/xml/9/28069/lc12729e.pdf , 25/08/07

ANMYF, http://www.google.com.mx/search? $\mathrm{hl}=\mathrm{es} \& \mathrm{q}=\mathrm{anmyf} \& \mathrm{meta}=\mathrm{cr} \% 3$ DcountryM X, 22/08/07.

BM, http://cgap.org/portal/binary/com.epicentric.contentmanagement.servlet.ContentDeliveryServlet/Press/sp_press_coverage38.html, 15/08/07 y http://www.bancomundial.org/siglas.htm, 16/08/07.
BANCOSOL, http://www.bancosol.com.bo/, $13 / 08 / 07$

BANSEFI,http://www.bansefi.gob.mx/, 12/08/07.

COMACREP, http://www.comacrep.org.mx/ , 15/08/07

CONMUJER, http://www.michoacan.gob.mx/ gobierno/conmujer.php, 10/08/07.

Desjardins, http://www.desjardins.com/en/, 20/08/07.

EMPRENDEDORES, http://tesoreria.nl.gob. $\mathrm{mx} /$ InformacionFinanzasT/CuentaPubli$\mathrm{ca} / 2001 /$ Organismos/30emprendedores, $14 / 08 / 07$ 
Esquivel Martínez, Horacio, Microcrédito vs. Pobreza, http://ejecutivosdefinanzas.org. $\mathrm{mx} /$ articulos.php?id_sec $=30 \& i d \_a r t=392$ , 15/08/07.

FIRCO/DownloadSrv\%3Fnombre\%3DCajaspo pulares.pdf+caja+popular+mexicana\&hl=e $\mathrm{s} \& \mathrm{ct}=\mathrm{clnk} \& \mathrm{~cd}=9 \& \mathrm{gl}=\mathrm{mx}, 18 / 08 / 07$.

FOJAL, http://fojal.jalisco.gob.mx/index.html, 25/08/07.

FONDESO, http://www.fondeso.df.gob.mx/, 12/08/07. y http://www.fondeso.df.gob. $\mathrm{mx} /$ noticias/detalleNoticias.html?id_noticia=12, http://www.fondeso.df.gob.mx/ memoria/3er_taller/AMNYF.pdf, http:// www.fondeso.df.gob.mx/noticias/detalleNoticias.html?id_noticia=12, 13/08/07.

Imperial Zúñiga, Ramón, Consolidación y Transformación de la Caja Popular Mexi- cana, http://64.233.169.104/search?q=cac he:D7R53wWpePIJ:soporte.sagarpa.gob. mx:9090/SAG-

Kart Koenigsfest, http://www.bancosol.com. bo/sp/intro.html, 15/08/07.

PRODESARROLLO, http://www.prodesarro1lo.org/boletin/pd_edicion04-04.pdf, 20/08/07.

Puente Ibarnegaray, Gonzalo, Primer Foro de Banca Social de la Ciudad de México, abril 2006. http://www.sra.gob.mx/internet/ agronuevo/num13/11_Rese_a_eventos. pdf, 15/08/07.

Yunus, Muhammad, videos, http://search.cnn. $\mathrm{com} / \mathrm{search} . j \mathrm{sp}$ ?query=yunus\&type=web\& sortBy $=$ date \&intl $=$ true, $10 / 08 / 07$.

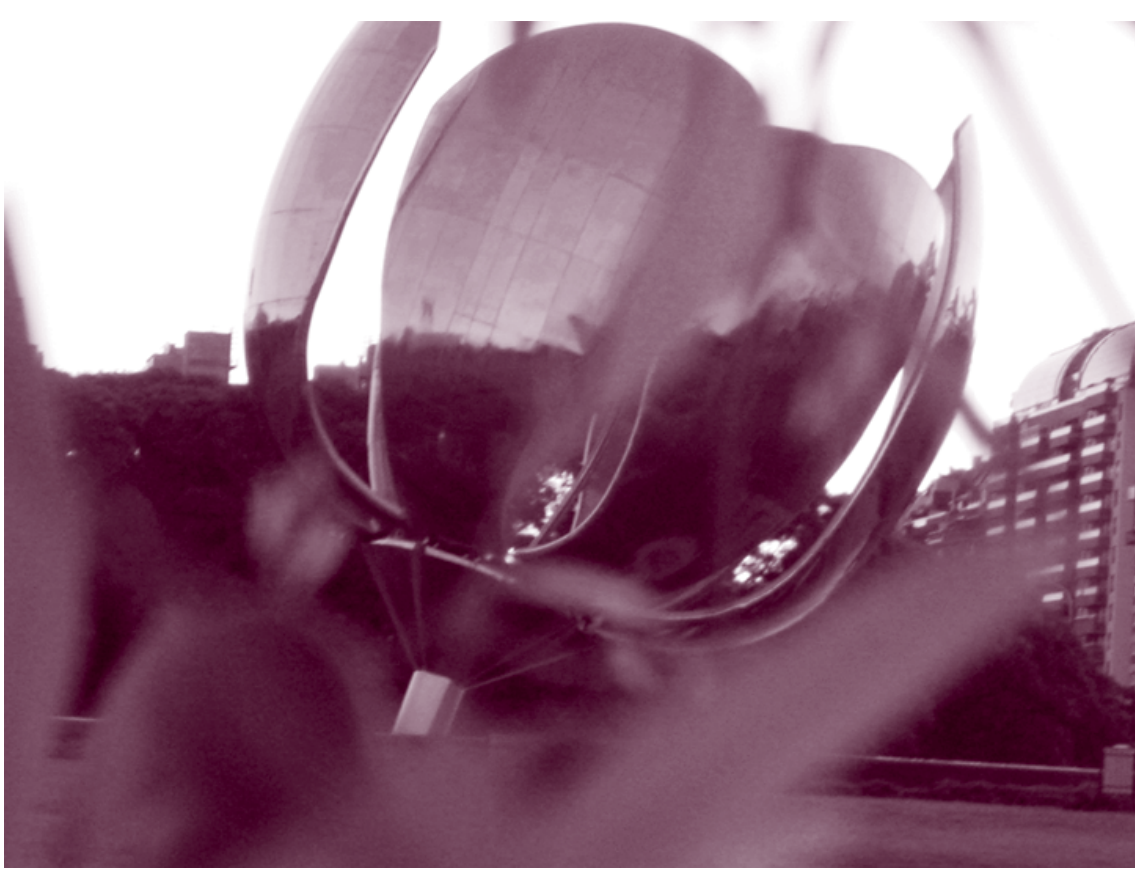

La flor IV. Buenos Aires, verano 2005-2006. PAI 